Journal of Applied Pharmaceutical Science Vol. 6 (01), pp. 137-146, January, 2016

Available online at http://www.japsonline.com

DOI: $10.7324 / \mathrm{JAPS} .2016 .600122$

ISSN 2231-3354 (cc) BY-NC-SA

\title{
Cytoprotective and antiinflammatory effect of polyphenolic fraction from Red cabbage (Brassica oleracea Linn var. capitata f rubra) in experimentally induced ulcerative colitis
}

\author{
Pramod Chandrasenan ${ }^{1 *}$, V M Anjumol ${ }^{1}$, M V Neethu $^{1}$, Raj Selvaraj ${ }^{1}$, Vysakh Anandan ${ }^{2}$, Gikku Martin Jacob ${ }^{2}$ \\ ${ }^{1}$ Department of Pharmacology, University College of Pharmacy, M.G University, Kottayam, Kerala, India. \\ ${ }^{2}$ Department of Biochemistry, St.Thomas College, Palai, Kottayam, Kerala, India.
}

\begin{tabular}{l} 
ARTICLE INFO \\
\hline Article history: \\
Received on: 01/10/2015 \\
Revised on: 28/10/2015 \\
Accepted on: $14 / 11 / 2015$ \\
Available online: $26 / 01 / 2016$ \\
\hline Key words: \\
Polyphenol, Red cabbage, \\
Colitis, Anti-inflammatory, \\
Cycloxygenase, \\
Antioxidant.
\end{tabular}

\begin{abstract}
In present study we investigated the anti-inflammatory effect of polyphenolic fraction isolated from Red cabbage Brassica oleracea Linn var. capitata f. rubra (PBO) on lipoplysacharide (LPS) stimulated HT-29 colonocytes and in rats with acetic acid induced colitis. Our results from in vitro studies demonstrated that PBO effectively attenuated the inflammatory response produced by cycloxygenase (COX), 5-lipoxygenase (5-LOX) and oxidative stress created via reactive oxygen species (ROS) and nitric oxide (NO) in LPS treated HT-29 cells. Additionally PBO down regulated the mRNA expression of inflammatory marker genes like COX-2, inducible nitric oxide (iNOS) tumor necrosis factor $\alpha$ (TNF- $\alpha$ ), interleukin-6 (IL-6) in HT-29 cells. PBO at a dose of $200 \mathrm{mg} / \mathrm{kg}$ body weight was tested in treatment groups of animals $(n=6)$ for 14 consecutive days after induction of colitis. The colonic mucosal injury was assessed by histological examination. Moreover, PBO administration markedly increased the mucin content as evidenced in periodic acid Schiff (PAS) staining and the mucosal content of lipid peroxidation (LPO), confirms that PBO could significantly inhibit colonic mucosal damage. These results indicated that PBO exert marked anti-inflammatory effect in experimental colitis, possibly by regulating the antioxidant and inflammatory mediators.
\end{abstract}

\section{INTRODUCTION}

Ulcerative colitis (UC) is an inflammatory disease of the large bowel which is more common in the Western and Northern hemispheres; the incidence is low in Asia and the Far East. It is slightly more common in women than in men. The prevalence of ulcerative colitis ranges from 10 to 70 per 100,000 people (Loftus et al., 2000). The major etiologic factors leading to ulcerative colitis include genetic factors, immune system reactions, and environmental factors, use of Non-Steroidal AntiInflammatory Drug's (NSAID), low levels of antioxidants, psychological stress factors, chronic smoking, and lactose intolerance. The disease is characterized by the inflammatory response of unknown origin associated with mucosal injury leading to increased epithelial permeability of lamina propria or

\footnotetext{
* Corresponding Author

Pramod Chandrasenan, Department of Pharmacology, University College of Pharmacy, M. G University, Kottayam, Kerala, India. Email: clinpramod@gmail.com
}

sub epithelial invasion of commensal bacteria and neutrophils recruitment (Fournier and Parkos, 2012). The pathogenesis of disease includes the presence of highly activated inflammatory cells such as neutrophils, dendritic cells, macrophages, and excessive production of ROS. This contribute the recruitment of production of various proinflammatory mediators such as cyclooxygenases (COX-1, COX-2), tumor necrosis factor-alpha (TNF$\alpha$ ), interleukin-6 (IL-6), and interleukin-12 (IL-12) (Xavier and Podolsky, 2007). Recent studies shows that many polyphenolic compounds have an intestinal anti-inflammatory activity and are capable of inhibiting proinflammatory markers associated with ulcerative colitis and inflammation (Gonzalez et al., 2011; Abboud et al., 2008).

From the above context, polyphenols isolated from plant have important role in the investigation of new safe therapeutics agents against inflammatory diseases. Red cabbage (Brassica oleracea var. capitata f. rubra), is a herbaceous, biennial, dicotyledonous flowering plant, indigenous to Mediterranean region and southwestern Europe (Shama et al., 2012). 
It is also known as purple cabbage due to its purple/red coloured leaves with a pigment belonging to anthocyanins (flavins). The change in colour varies according to $\mathrm{pH}$ of the soil. In acidic soils, the leaves grow more reddish, in neutral soils they grow purple, while an alkaline soil will produce rather greenishyellow coloured cabbages. It has been reported that red cabbage is a rich source of minerals, natural antioxidants such as ascorbic acid, a-tocopherol, b-carotene and lutein (Singh et al., 2006), oligosaccharides, and a number of bioactive substances, such as favonols, glucosinolates (Wiczkowski et al., 2013). Cabbage has widespread use in traditional medicine due to its antioxidant, antiinflammatory and antibacterial properties. It is used in treatment of symptoms associated with gastrointestinal disorders like peptic and duodenal ulcers, gastritis and irritable bowel syndrome (Sami et al., 2013).

Previously red cabbage has been reported to have a wide range of biological activities such as hypocholesterolaemic, hepato-protective, neuroprotective and anti-diabetic effects (Park et al., 2014). Recent analysis of chromatograms from HPLC suggests malvidin glycosides including malvidin 3-glucoside (oenin), malvidin 5-glucoside and malvidin 3, 5-diglucoside in red cabbage juice could inhibit IL-6 secretion of LPS-stimulated splenocytes (Jin-Yuarn et al., 2008). Red cabbage is rich sources of phenolic compounds, anthocyanins being the most abundant class, have potent antimicrobial action (Arapitsas 2008; RandHafidhet al., 2011). Some researchers have been conducting studies to quantify the phenolic compounds, carotenoids, vitamin $\mathrm{C}$ and antioxidant potential of red cabbage (Nilsson et al., 2006; Kusznierewicz et al., 2008). The antioxidant properties were tested in many studies by using different approaches (Liu et al., 2008; Zanfini et al., 2010). The main objective of the study is to evaluate the anti inflammatory effect of $\mathrm{PBO}$ on in vitro and in vivo models of ulcerative colitis.

\section{MATERIALS AND METHODS}

\section{In vitro studies}

\section{Chemicals}

All chemical used in this study are of analytical reagent grade. Biochemical reagents were purchased from Merck, India. Tissue culture plates were purchased from Tarson, India. RT-PCR kit was purchased from Eppendorf India Ltd, Chennai.

\section{Collection of plant material}

The red cabbage was purchased from the local market in Kottayam, Kerala, India. A voucher specimen No: 747 was preserved at University College of Pharmacy, Cheruvandoor Campus. M. G. University. Collected material was washed thoroughly with water and dried under shade to remove the moisture, then coarsely powdered by using electric grinder.

\section{Extraction procedure}

Hundred grams of red cabbage powder was soaked in $70 \%$ ethanol $(1: 5 \mathrm{w} / \mathrm{v})$ at room temperature $\left(25 \pm 1{ }^{0} \mathrm{C}\right)$. After $24 \mathrm{~h}$, the supernatant was decanted and the residue was re-soaked in respective fresh solvent. The process was repeated three times for complete extraction (Maheswari et al., 2011).

\section{Isolation of polyphenolic fraction of Brassica oleracea var. capitata f. rubra}

Five grams of obtained crude extract was dissolved in $100 \mathrm{ml}$ water and sequentially extracted thrice using $100 \mathrm{ml}$ hexane and ethyl acetate. Then solvent in the each fractions were removed using rotary evaporator to obtain ethyl acetate fraction as phenolic rich fraction (Maheswari et al., 2011). Folin-Ciocalteau reagent was used for the estimation of total polyphenol content of the solution (Gutfinge, 1981).

\section{Cell culture and treatments}

The human colon cell line HT-29 cells, purchased from NCCS Pune was grown in plastic culture flask in Dulbecco's Modified Eagle's Medium (DMEM) with L-glutamine supplemented with $10 \%$ fetal bovine serum (FBS) and $1 \%$ antibiotic/antimycotic solution (penicillin/streptomycin) under 5\% $\mathrm{CO}_{2}$ at $37{ }^{\circ} \mathrm{C}$. After 4-5 days, cells were removed from culture flask by scraping and centrifuged at $1500 \mathrm{rpm}$ for $10 \mathrm{~min}$. The medium was then removed and the cells resuspended with fresh DMEM. Cells counts and viability were performed using a standard trypan blue cell counting technique. The cell density was adjusted to $1 \times 10^{6}$ cells $/ \mathrm{ml}$ in the same medium. About $100 \mu \mathrm{l}$ of the suspension were cultured in 96-well plates for one day to become nearly confluent. Cells were treated with LPS (final concentration of $1 \mu \mathrm{g} / \mathrm{ml}$ ) for activating inflammatory response. Various concentrations of the samples were prepared from the stock solutions in DMSO by serial dilution in DMEM to give a volume of $100 \mu \mathrm{l}$ added to each well of a microtiter plate (96-well). The cells were incubated for 24 hours after the addition of extracts, vehicle, and positive control $(10 \mu \mathrm{g} / \mathrm{ml})$. Cells were harvested and lyses using cell lysis buffer and performed various assays that determines the anti-inflammatory effect of extract.

\section{Cell viability assay}

Cell viability was assayed by the modified tetrazolium salt 3-(4-5- dimethylthiozol-2-yl) 2-5- diphenyl-tetrazolium bromide (MTT) assay (Pandey et al., 2007).

\section{Determination of total Cyclooxygenase activity}

The total Cyclooxygenase activity was measured according to the method described by (Shimizu et al., 1981). The assay mixture contained Tris $\mathrm{HCl}$ buffer, glutathione, hemoglobin and enzyme. The reaction was initiated by the addition of arachidonic acid followed by incubation at $37^{\circ} \mathrm{C}$ for 20 minute. The reaction was terminated by addition of $0.2 \mathrm{ml}$ of $10 \%$ TCA in $1 \mathrm{~N} \mathrm{HCl}$. The above reactants were mixed, $0.2 \mathrm{ml}$ of TBA was added and contents were heated in a boiling water bath for 20 minute. The contents were cooled and centrifuged at $1000 \mathrm{rpm}$ for 3 minute. The absorbance of the supernatant was measured at $632 \mathrm{~nm}$. 


\section{Determination of 5- Lipoxygenase activity}

Determination of 5-LOX activity was measured according to the method of Axelrod et al., 1981. The reaction was carried out in a quartz cuvette at $25^{\circ} \mathrm{c}$ with $1 \mathrm{~cm}$ light path. The assay mixture contained $2.75 \mathrm{ml}$ of tris buffer of $\mathrm{pH} 7.4,0.2 \mathrm{ml}$ of sodium linoleate and $50 \mu 1$ of enzyme. The increase in O.D was measured in $234 \mathrm{~nm}$.

\section{Estimation of nitrate level}

Nitrite level was determined according to the method of Gillium et al., 1993 . To $0.05 \mathrm{ml}$ of sample $0.1 \mathrm{ml}$ of sulphosalicylic acid was added and vortexed well for 30 minutes. The samples were then centrifuged at $5000 \mathrm{rpm}$ for 15 minutes. The protein free supernatant was used for the estimation of nitrate levels. To $200 \mu \mathrm{l}$ of the supernatant, $30 \mu \mathrm{l}$ of $10 \% \mathrm{NaOH}$ was added followed by $300 \mu \mathrm{l}$ of Tris $\mathrm{HCl}$ buffer and mixed well. To this $500 \mu \mathrm{l}$ Greiss reagent was added. Sodium nitrate was used as the standard. The amount of nitrate $(\mu \mathrm{g})$ present in the sample was estimated from the standard curve obtained.

\section{Reverse transcription-polymerase chain reaction}

The gene level expression of COX-2, TNF- $\alpha$, iNOS, IL- 6 mRNA was measured by semi-quantitative Reverse TranscriptionPolymerase Chain Reaction (RT-PCR). HT-29 cells (wells of 60$70 \%$ confluency) were treated with PBO $(10 \mu \mathrm{g} / \mathrm{ml})$. A control was also maintained without adding any samples. Diclofenac $(10 \mu \mathrm{g} / \mathrm{ml})$ used as standard. After 24 hour incubation the cells were harvested and RNA was isolated by Trizol method. For cDNA synthesize, two step RT-PCR kit was used following manufacturers procedure.

RT-PCR was performed in an Eppendorf thermocycler by using forward and reverse primers of COX-2, TNF- $\alpha$, iNOS, IL-6. GAPDH primers were used as an internal control. The sequences of the primers used are shown in Table 1. The PCR products were separated by electrophoresis on $1.5 \%$ agarose gel containing ethidium bromide, visualized under a UVtransilluminator and the relative intensities of bands of interest were measured on a GelDoc 2000 scanner (Bio-Rad, CA, USA) with scan analysis software.

\section{Fluorescent staining of ROS production in HT-29 cells}

Cells $\left(1 \times 10^{5}\right)$ were seeded on a 96 well black multi-liter plate with clear bottom, and they were allowed to grow overnight. The cells were washed twice with PBS and incubated with $0.1 \%$ BSA in PBS containing 5 $\mu \mathrm{M}$ DCFDA (dissolved in $0.2 \%(\mathrm{v} / \mathrm{v})$ ethanol) for 30 minute at $37^{\circ} \mathrm{C}$. The cells were washed twice with PBS again and then incubated with fresh medium containing $500 \mu \mathrm{M}$ NADPH (Final Concentration). The pictures were taken in Blue excitation (Excitation wavelength 450-480nm: Emission wavelength $515 \mathrm{~nm}$ ) Olympus CKX41 epifluorescent microscopy with Optika (Italy) imaging system.

\section{In vivo studies \\ Animals}

Healthy adult Albino wistar male rats between 4-8 weeks of age and weighing150-200g bred in the host department animal facility were used for the study. Animals were housed in polypropylene cages at a temperature of $25-30^{\circ} \mathrm{C}$ and relative humidity $35-45 \%$, in light and dark cycles of $12 \mathrm{am}$ and $12 \mathrm{pm}$ hour respectively for one week before and during the experiments. Animals were provided with standard rodent pellet diet (Dayal Industries, Banglore) and water. All experiments were conducted as per the guidelines of the animal ethics committee CPCSEA (Registration No.499/CPCSEA) according to Government of India accepted principles for laboratory animals' use and care.

\section{Experimental design and induction of colitis}

Rats were divided into 4 groups ( $n=6$ per group). Group I were kept as normal and received no treatment. Group II, III, IV were subjected to the induction of ulcerative colitis by intracolonic injection of $2 \mathrm{ml}$ acetic acid (AA) (4\% v/v). Group II served as ulcerative colitis control group. Group III was treated with standard drug sulfasalazine (SA) $(100 \mathrm{mg} / \mathrm{kg}$. B.wt) p.o and Group IV was treated with PBO $200 \mathrm{mg} / \mathrm{kg}$ p.o for 14 consecutive days. The animals were sacrificed $15^{\text {th }}$ day of experiment for estimation of various biochemical parameters and histopathology (macroscopic and microscopic). For histological analysis, colon tissues were dissected, fixed in $10 \%$ buffered formalin and then decalcified for 7 days in 20\% EDTA.

\section{Estimation of lipid peroxidation (LPO) on colon tissue}

Lipid peroxidation, an indicator of mucosal injury induced by reactive oxygen species were measured according to the method described previously (Ohkawa et al., 1979). Briefly, 0.5 $\mathrm{ml}$ of colon tissue homogenate is mixed with $2 \mathrm{ml}$ of TBA reagent containing $0.375 \%$ TBA (Thiobarbituric acid), $15 \%$ trichloroacetic acid and $0.25 \mathrm{~N} \mathrm{HCl}$. The mixture was then boiled for $15 \mathrm{~min}$, cooled and centrifuged (2000 rpm; $15 \mathrm{~min})$. Absorbance of the supernatant was measured at $532 \mathrm{~nm}$. Lipid peroxide levels were expressed as mmol of malondialdehyde produced.

Table 1: Sequences of the primers used for the study.

\begin{tabular}{|c|c|c|}
\hline Gene & Forward primer & Reverse primer \\
\hline $\mathrm{COX}-2$ & 5' TCTGATCAATGTCATGAGCAAAGG 3' & 5'TCTGATCAATGTCATGAGCAAAGG 3' \\
\hline iNOS & 5'ACAACAAATTCAGGTACGCTGTG3' & 5'TCTGATCAATGTCATGAGCAAAGG3' \\
\hline $\mathrm{TNF}-\alpha$ & 5' CCAGGGACCTCTCTCTAATCAGC3' & 5'CTCAGCTTGAGGGTTTGCTACAA3' \\
\hline IL-6 & 5' CCTTAAAGCTGCGCAGAATG3' & 5' ATTCAATGAGGAGACTTGCC3'. \\
\hline GAPDH & 5'TCCATGACAACTTTGGTATCGTG3' & 5'ACAGTCTTCTGGGTGGCAGTG3' \\
\hline
\end{tabular}


The colon tissue were dissected out and tissue sections $(5 \mu \mathrm{m})$ fixed by immersion at room temperature in $10 \%$ formalin solution. For the histological examinations, paraffin-embedded tissue sections of colon tissue were stained with hematoxylineosin (H\&E). Goblet cell numbers were quantified in periodic acid Schiff (PAS) stain at $\times 200$ magnifications. All tissue sections were examined blindly with respect to the source of the tissue and counts were determined at three different mucosal areas for each of the three sections per rat.

\section{Statistical analysis}

All statistical analysis were carried out using SPSS/PC+, version 11.0 (SPSS Inc., Chicago, IL, USA) and the results were represented as mean \pm S.E.M. For the comparison test of significant differences among groups One-way ANOVA was performed followed by Duncan's multiple range tests. Level of significance was set at $\mathrm{P}<0.05$.

\section{RESULTS}

\section{Determination of total phenolic content}

Total phenolic content of ethyl acetate fraction was found to be 5.686 gram equivalent of gallic acid per 100 gram of fraction

\section{Effect of PBO on cell viability in HT-29 cells}

In order to determine the cell viability of PBO, HT-29 cells was incubated for $24 \mathrm{hr}$ with $\mathrm{PBO}$ at a wide range of concentrations $(6.25-100 \mu \mathrm{g} / \mathrm{l})$ and cell viability was evaluated by MTT assay. The percentage viability obtained in the different concentrations of sample extract was depicted in figure 1 .

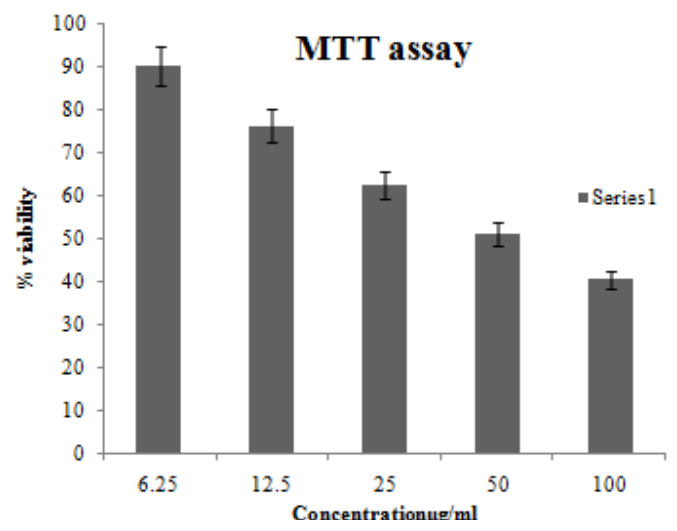

Fig. 1: Effect of $P B O$ on cell viability of HT-29 cells. Values are expressed as mean $\pm \operatorname{SEM}(\mathrm{n}=6)$

\section{Effect of PBO on total Cyclooxygenase activity in HT-29 cells}

The total COX activity was increased during addition of LPS in HT-29 cells. The different concentration of PBO shows inhibition in total COX activity.

The sample at concentration of $10 \mu \mathrm{g} / \mathrm{ml}$ shows $68.75 \%$ inhibition of total COX activity in $1 \times 10^{6}$ cells $/ \mathrm{ml}$. Data were represented as mean \pm SEM of triplicate determination (figure 2).

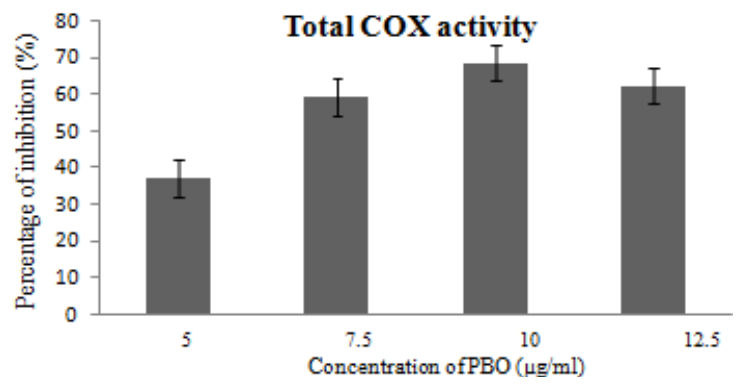

Fig. 2: Effect of PBO on total Cyclooxygenase activity in HT-29 cells: HT29 cells were pre-treated with LPS $(1 \mu \mathrm{g} / \mathrm{ml})$ concentration for $1 \mathrm{hr}$ and then incubated with PBO at various concentrations $(\mu \mathrm{g} / \mathrm{ml})$ for $24 \mathrm{hrs}$. Data were represented as mean \pm S.E.M. of three separate experiments.

\section{Effect of PBO on 5-LOX activity in HT-29 cells}

The 5-LOX activity was increased during addition of LPS in HT-29 cells. The different concentration of PBO shows inhibition in 5-LOX activity. The sample at concentration of $10 \mu \mathrm{g} / \mathrm{ml}$ shows $27.18 \%$ inhibition of 5 -LOX activity in $1 \times 10^{6}$ cells $/ \mathrm{ml}$. Data were represented as mean \pm SEM of triplicate determination (figure 3 ).

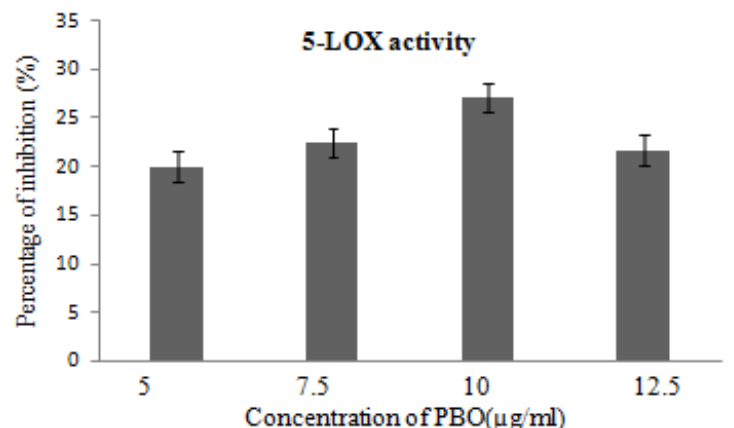

Fig. 3: Effect of PBO on 5-LOX activity in HT-29 cells: HT-29 cells were pretreated with LPS $(1 \mu \mathrm{g} / \mathrm{ml})$ concentration for $1 \mathrm{hr}$ and then incubated with PBO at various concentrations $(\mu \mathrm{g} / \mathrm{ml})$ for $24 \mathrm{hrs}$. Data were represented as mean \pm S.E.M. of three separate experiments.

\section{Effect of PBO on nitrate level in HT-29 cells}

The amount of LPS induced nitrate production is statistically reduced $(\mathrm{P}<0.05)$ at $10 \mu \mathrm{g} / \mathrm{ml}$ concentration of $\mathrm{PBO}$ when compared with control (treated with LPS alone). The results were depicted in figure 4.

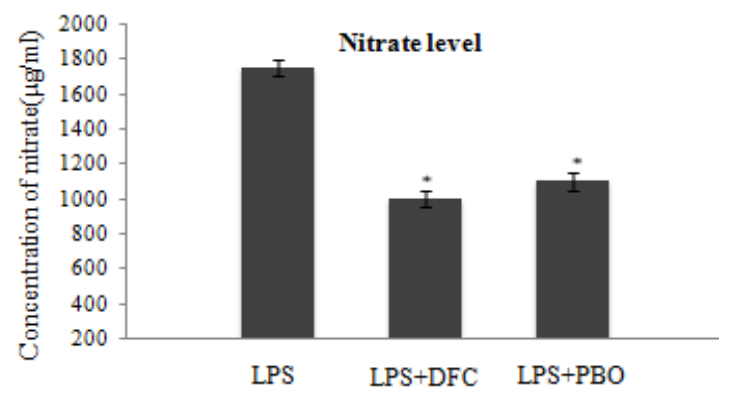

Fig. 4: Effect of PBO on nitrate level in HT-29 cells: HT-29 cells were pretreated with LPS $(1 \mu \mathrm{g} / \mathrm{ml})$ concentration for $1 \mathrm{hr}$ and then incubated with PBO and DFC at a concentration of $10 \mu \mathrm{g} / \mathrm{ml}$ for $24 \mathrm{hrs}$. Data were represented as mean \pm S.E.M. of three separate experiments. ${ }^{*}$ Statistical difference with control group at $P<0.05$. 


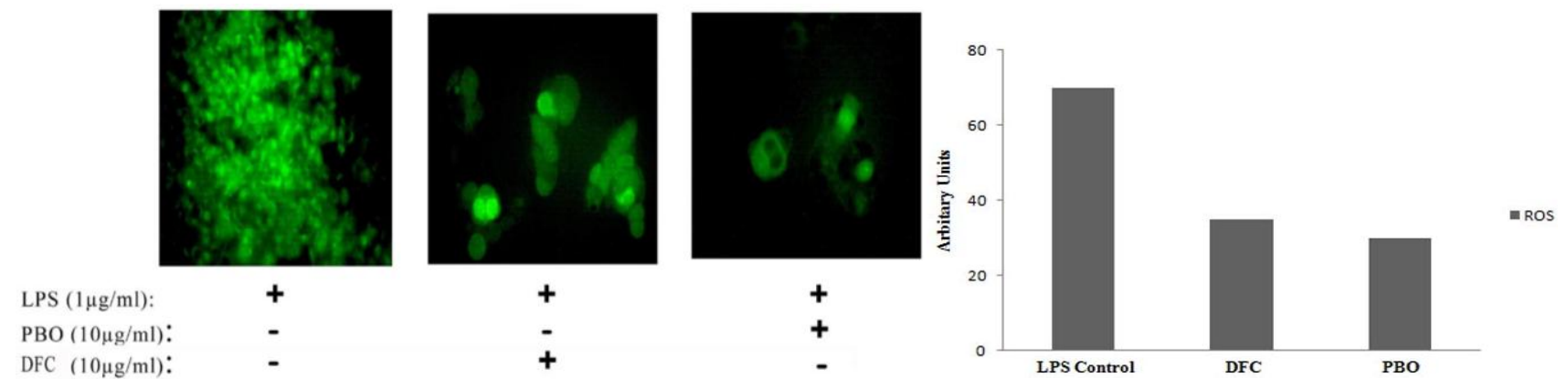

Fig. 5: Effect of PBO on ROS in HT-29 cells: Fluorescent staining of ROS production in HT-29 cells treated with PBO and diclofenac standard (DFC) at a concentration of $10 \mu \mathrm{g} / \mathrm{ml}$. DCFDA was used as the fluorescent dye and pictures were taken in Blue excitation (Excitation wavelength $450-480 \mathrm{~nm}$ : Emission wavelength $515 \mathrm{~nm})$.

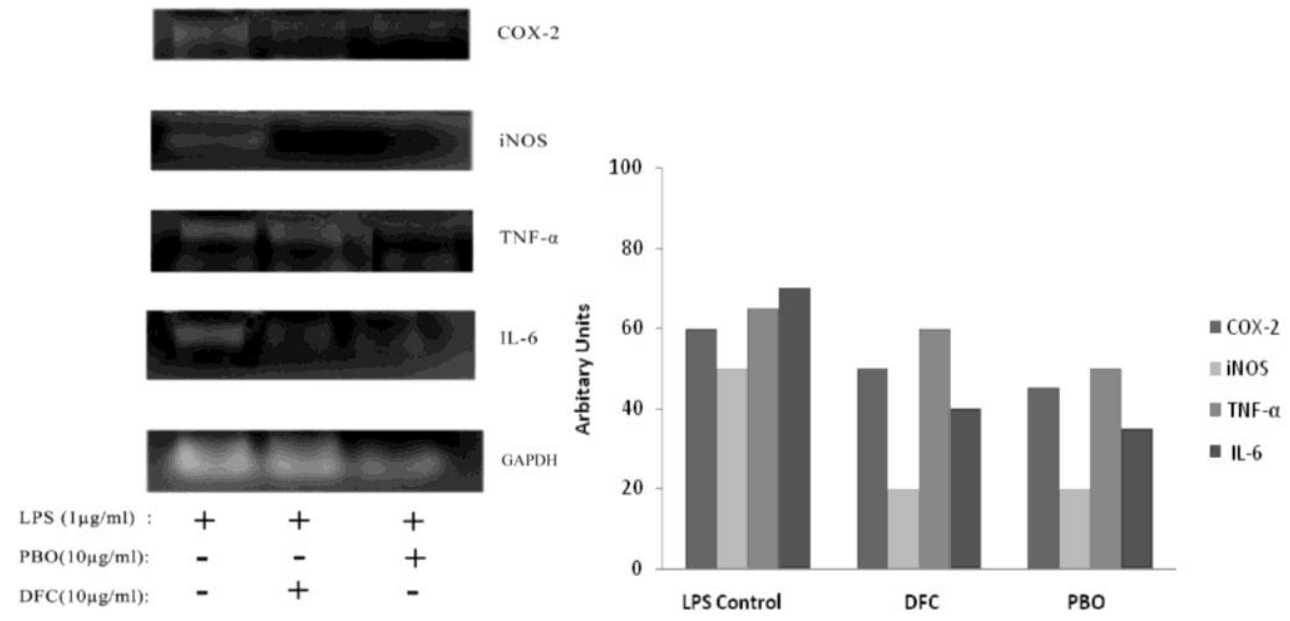

Fig. 6: RT-PCR gel of COX-2, iNOS, IL-6, TNF- $\alpha$ mRNA in HT-29 CELLS: Inhibitory effect of PBO on the expression of the proinflammatory markers like COX-2, iNOS and cytokines like IL-6, TNF- $\alpha$ was determined by reverse transcriptase-PCR, as described in the materials and methods section. GAPDH was used as a control. The gene expression of COX-2, iNOS, IL-6, TNF- $\alpha$ in LPS stimulated group is upregulated. Downregulated expression of COX-2 and iNOS IL-6, TNF- $\alpha$ were seen in PBO treated group as compared to LPS treated group.

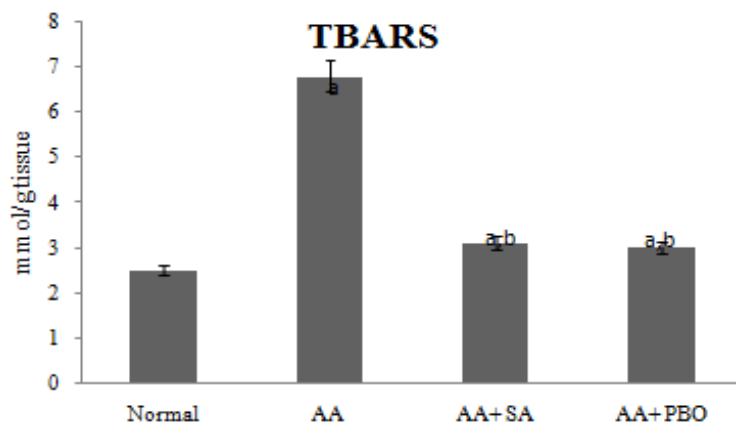

Fig. 7: Effect of PBO on concentration of TBARS. Values expressed as average of 6 samples \pm SEM in each group. a - Statistical difference with control group at $P<0.05 . \mathrm{b}-$ Statistical difference with adjuvant group at $P<0.05$.

\section{Effect of PBO on ROS in HT-29 cells}

Reactive oxygen species production was increased during stimulation of HT-29 cells with LPS. Fluorescence intensity shows that ROS production was significantly reduced by the supplementation of PBO as compared to the control (figure 5).

\section{Effect of PBO on COX-2 and iNOS gene expression in HT-29 cells}

The mRNA expression of inflammatory marker genes like COX-2 and iNOS in HT-29 cells was up regulated during LPS regulate the expression of COX-2 and iNOS genes as compared to control (figure 6).

\section{Effect of PBO on TNF- $\alpha$ and IL-6 gene expression in HT-29 cells}

During LPS stimulation in HT-29 cells, mRNA expression of cytokines like TNF- $\alpha$ and IL- 6 was markedly increased. Addition of PBO $(10 \mu \mathrm{g} / \mathrm{ml})$ down regulates the expression of TNF- $\alpha$ and IL- 6 genes as compared to control group (figure 6). 


\section{Effects of PBO on lipid peroxidation}

The effect of PBO on the colon tissue lipid peroxidation level is illustrated in Figure. Induction of acetic acid in rats exhibited an increased level of LPO in colon tissue, evidenced by the elevated levels of TBARS. Treatment with PB0 $(200 \mathrm{mg} / \mathrm{kg})$ significantly $(P<0.05)$ decreased the LPO $(3.0 \pm 0.02 \mathrm{mmol} / \mathrm{g}$ tissue) compared to AA induced group $(6.80 \pm 0.03 \mathrm{mmol} / \mathrm{g}$ tissue $)$. The LPO in normal animals were found to be $2.5 \pm 0.01 \mathrm{mmol} / \mathrm{g}$ tissue.

\section{Effect of PBO on histopathology of colon tissue}

Effect of PBO on AA induced colitis histopathology (H\&E) is shown in (Figure 8). Pictures are shown from representative colon tissue samples of experimental animals collected on day $15^{\text {th }}$ post AA induction. As expected, normal group had no remarkable changes to their tissue cyto architecture. In contrast, colitis control group exhibited severe colonic mucosal injury, epithelial necrosis and massive cellular infiltration of plasma cells, polymorphs with edema. While PBO treated colon tissue histopathology revealed minimal mucosal damage and edema with mild inflammatory cell infiltration and standard drug treated group also protects the host from colitis by showing minimal damage of colon epithelium.

PAS stained colon tissue of normal rat colon shows mucin secreting goblet cells $(100 \%)$ were replaced by granulation tissue $(0 \%)$ and necrotic tissue in AA group. The mucin secreting goblet cells are replaced by the administration of PBO $(70 \%)$ in $\mathrm{AA}+\mathrm{PBO}$ treated group (fig 9).

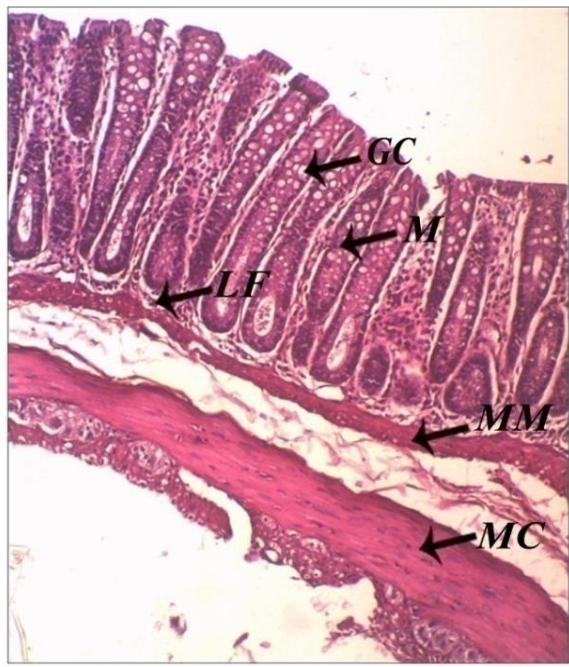

(A) Histopathology of colon tissue of normal rat Cross section of normal colon tissue mucosa $(\mathrm{M})$ shows numerous closely arranged tubular glands.Mucosal surface is lined by columna cells, amidst these with numerous goblet cells (GC). A good number of lymphatic follicles (LF) noted in the Lamina propria. Musculari mucosa (MM), submucosa and muscle coats (MC) are free from inflammation and hemorrhage.

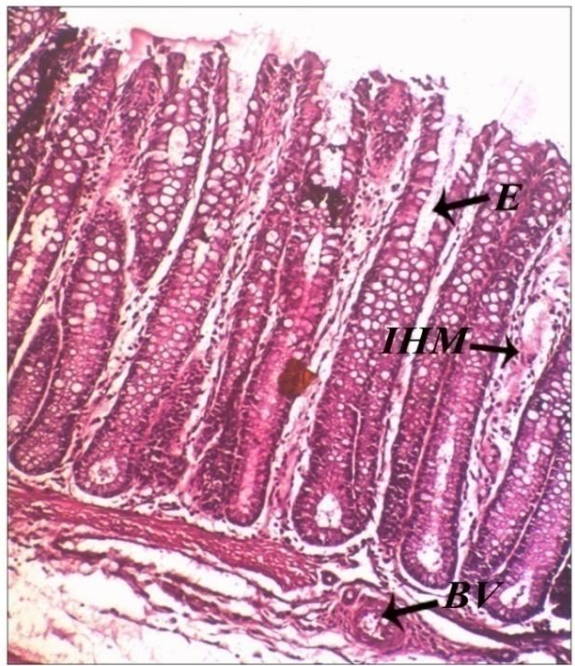

(C) Histopathology of colon tissue of AA+Sulfasalazine

Cross section of the colon tissue shows mildly inflamed and hyperemic mucosa, inflammations particularly in the muscularis mucosa, epithelium lining the glands are secretary. Some of the glands are swollen and edematous.

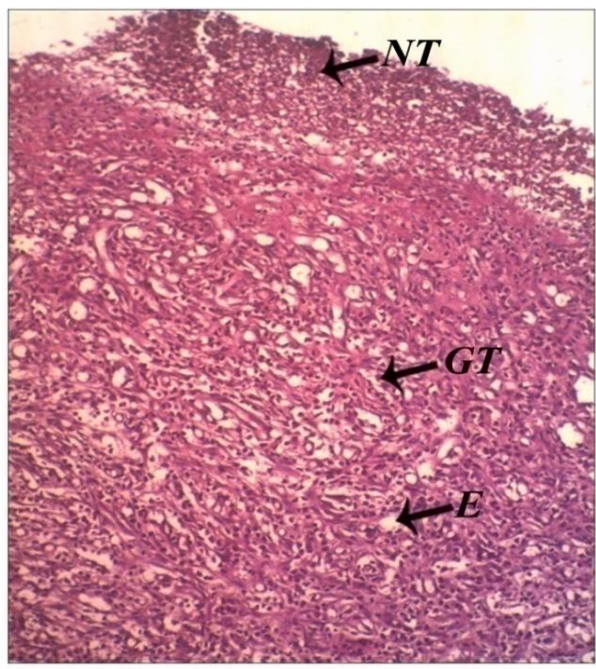

(B) Histopathology of colon tissue of AA rat

Cross section of acetic acid (AA) induced rat colon tissue shows edema (E) and the wall of the colon is thinner than the normal. The mucosa and submucosa have been replaced by vascula granulation tissue (GT) containing plenty of plasma cells, polymorphs,lymphocytes,similar type of cellular infiltration noted in the atrophic muscle coats and in the subserosa connective tissue.

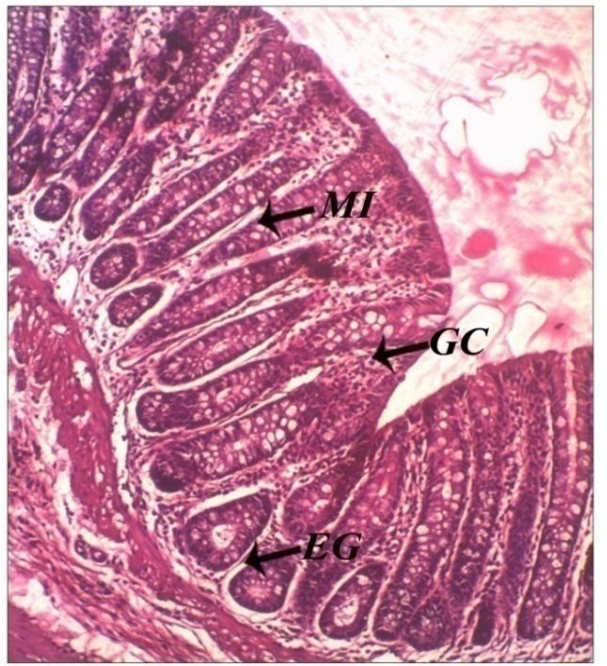

(D) Histopathology of colon tissue of $A A+P B O$ rat Cross section of the colon tissue shows mildly inflamed (MI) and hyperemic mucosa, inflammations particularly in the muscularis mucosa, epithelium lining the glands are secretary. Some of the glands are swollen and edematous (EG)

Fig. 8: Histology of colon tissue. 


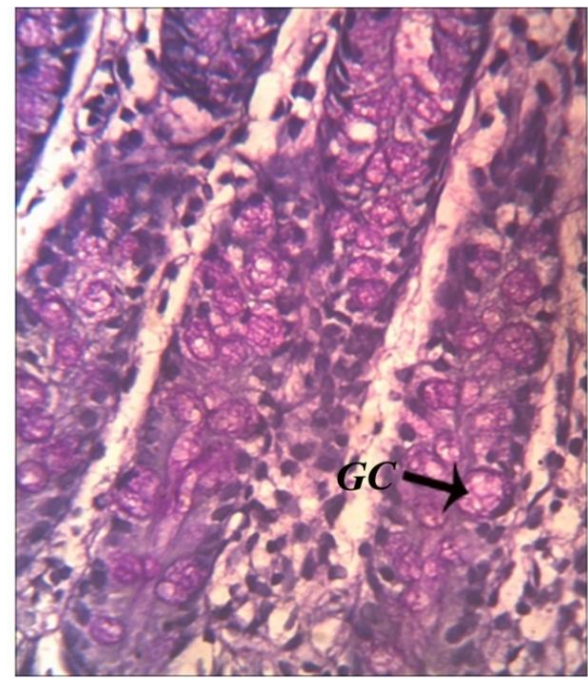

(A) PAS staining of colon tissue of normal rat

The PAS section shows mucosa lined numerous mucin secreting goblet cells ( $100 \%)(\mathrm{GC})$ with abundant mucin

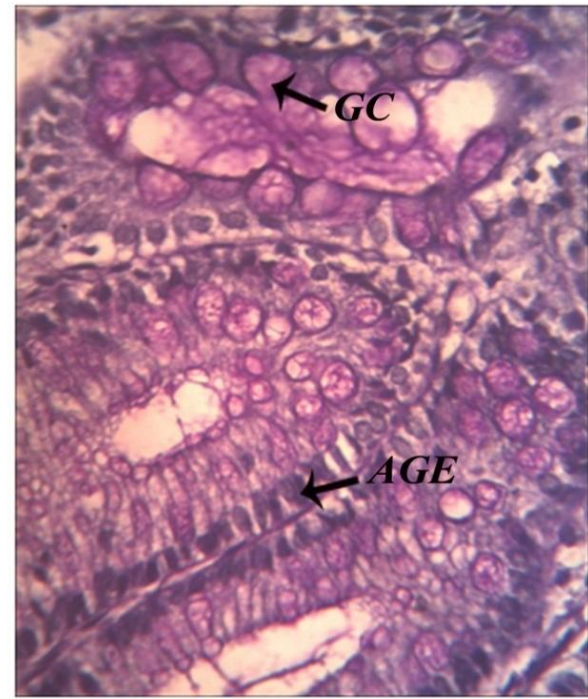

(C) PAS staining of colon tissue of $A A+$ Sulfasalazine rat The PAS section shows mucosa lined numerous mucin secreting (scanty secretion) goblet cells $(\mathrm{GC})(50 \%)$, rest of them are atrophic glandular epithelial tissue (AGE).

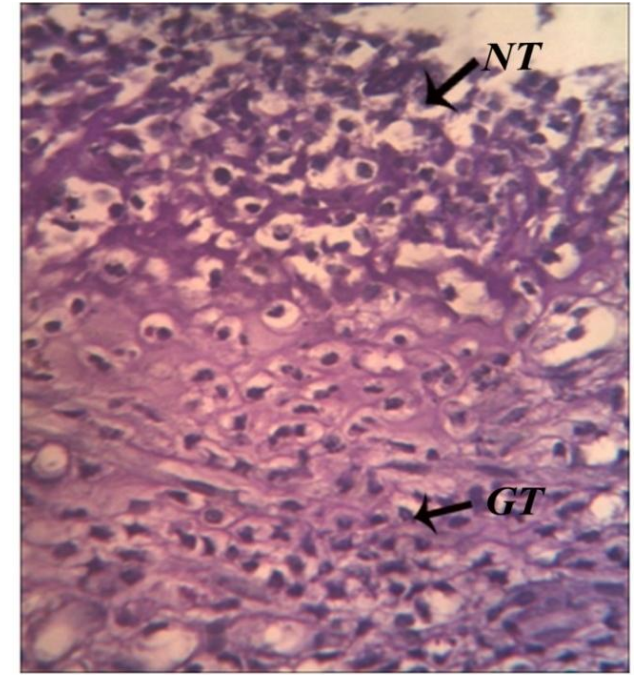

(B) PAS staining of colon tissue of AA rat

The PAS section shows all the layers are replaced by granulation tissue (GT) $(0 \%)$, necrotic tissue (NT) replaces muscularis mucosa.

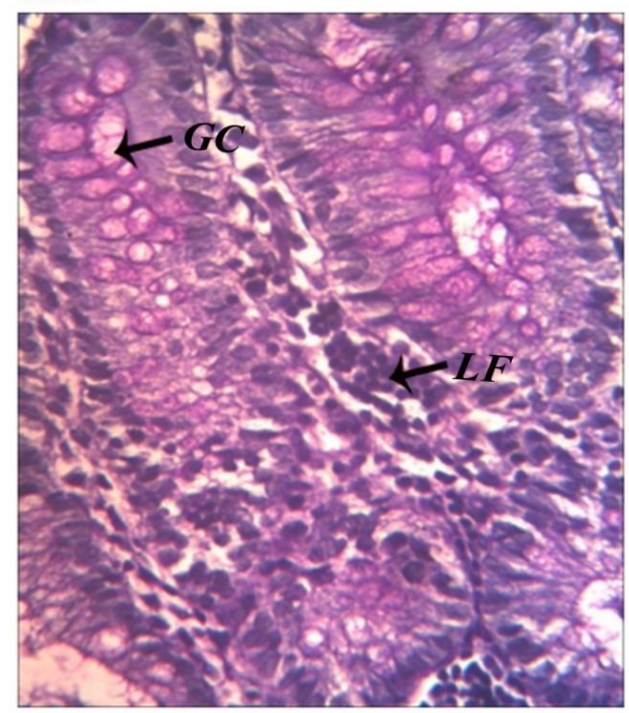

(D) PAS staining of colon tissue of $A A+P B O$ rat

The PAS section shows lymphoid follicles (LF) and mucosa lined numerous mucin secreting goblet cells (GC) $(70 \%)$.

Fig. 9: PAS staining of colon tissue.

\section{DISCUSSION}

Ulcerative colitis is an inflammatory bowel diseases (IBD) characterized by chronic inflammation of the large bowel (colon and rectum). The diseases may present with mucosal injury followed by the activation of inflammatory cells such as neutrophils, macrophages and dendritic cells. The highly activated inflammatory cells cause excessive productions of cytokines, adhesion molecules, and ROS (Cho et al., 2011). These may leads to various disease conditions like abdominal pain, vomiting, diarrhea, malena, weight loss, and secondary symptoms such as arthritis, pyoderma gangrenosum, and primary sclerosing cholangitis. HT-29 colon cells pretreated with LPS before one hour of the experiment may lead to production of various proinflammatory mediators like COX-2, TNF- $\alpha$, IL-6 etc. Increased expression of iNOS and enhanced level of nitrate was also associated with LPS stimulation. Pharmacologically reducing the levels of LPS-inducible inflammatory mediators is regarded as an effective therapeutic strategy for alleviating a variety of inflammatory disorders (Seung-Jun et al., 2014).

The mediators arising from the cyclo-oxygenase (COX) cascade and the role of biologically active prostaglandins in the inflammatory process and body homoeostasis have been extensively studied (Griswold and Adams1996). Under basal conditions, COX-2 expression is highly restricted; however, COX2 is dramatically upregulated during inflammation (Anderson et al., 1996). Development of ulcerative colitis was associated with increased expression of COX-2 (Konturek et al., 2009). In current 
study, the up regulated level of COX-2 after treatment with LPS reduced by supplementation of PBO. Increased percentage of inhibition of total COX activity in PBO treated sample indicates suppressed level of COX isoforms leading to the reduction of inflammation. Moreover, RT-PCR experiments in our study shows up regulated gene level expression of COX-2 gene. The down regulation of gene level expression COX-2 after treatment with PBO indicates its important role in pharmacology as a COX-2 inhibitor.

In addition, there is a growing body of evidence that the complex pathway of arachidonic acid metabolism in inflammation involves a variety of mediators other than the COX, all of which have a role in the overall process (Martel-Pelletier et al., 2003). Leucotrienes, which are the second main family of arachidonic acid derivatives, are synthesized from the activity of 5lipoxygenase (5-LOX) and have a major role in the inflammatory process. Enhanced activation of lipoxygenases and increased content of Leucotrienes are characteristic of ulcerative colitis (Singh et al., 2003). An elevated level of 5-LOX was observed in LPS stimulated HT-29 cells. Increased level of 5-LOX activity was suppressed by PBO treatment reveals the ability of PBO as a drug for treating inflammation associated to arachidonic pathway. Nitric oxide (NO) is known to mediate the inflammatory response by inhibiting or inducing inflammation via a variety of different pathways. NO has been shown to activate and inhibit the transcription factor, nuclear factor-kappa B (NF-kB). When NO activates NF- $\mathrm{KB}$ it induces the generation of proinflammatory cytokines such as tumor necrosis factor alpha (TNF- $\alpha$ ), which are thought to drive the chronic inflammatory response. NO is measured as nitrate levels using Greiss reagent and our results clearly shows decreased Nitrate levels in cells treated with PBO. Nitrate level was increased markedly after pretreatment with LPS in HT-29 cells. Reduction in nitrate level after PBO treatment indicates the decrease in production of proinflammatory cytokines. Recent research shown that nitric oxide and prostaglandin are the main inflammatory mediators take part in the pathogenesis of inflammatory bowel disease. This enhances the expression of iNOS and COX-2 in the colonic mucosa (Sakamoto, 1998; Kankuri et al., 1999). In ulcerative colitis, cytokines (interleukin$1 \beta$, interferon- $\gamma$ ) and LPS induce expression of iNOS leading to a steep rise of nitric oxide synthesis (Sklyarov et al., 2011). Down regulation of gene level expression of iNOS gene by $\mathrm{PBO}$ treatment reduce the NO level and protect cells from NO induced oxidative damage. Therefore, the inhibitory activity of PBO may be due to their anti-inflammatory properties and ability to counteract NO induced oxidative damage.

ROS play an important role in inflammation associated with UC. The uncontrolled activation of immune system results in the sustained overproduction of reactive metabolites of oxygen and nitrogen. It is thought that some of the intestinal and/or colonic injury dysfunction observed in IBD is due to the elaboration of these reactive species (Kevin-Pavlick et al., 2002). ROS production was increased during stimulation of HT-29 cells with LPS. The intensity of fluorescence in LPS induced HT-29 cells increased during DCFDA Fluorescent staining. The reduced fluorescent intensity in PBO treated group was due to the suppression of ROS generation. This indicate the anti oxidant power of $\mathrm{PBO}$ in protecting cells from oxidative damage caused by ROS in UC.

TNF- $\alpha$ is the major proinflammatory cytokine that plays an important role in pathogenesis of inflammatory bowel disease (Sands and Kaplan, 2007). TNF-alpha mediates multiple proinflammatory signals that play a central role in the pathogenesis of IBD, including neutrophil recruitment to local sites of inflammation, activation of both coagulation and fibrinolysis, and induction of granuloma formation (Targan et al., 1997). Moreover, enhanced secretion of TNF-alpha from lamina propria mononuclear cells has been found in the intestinal mucosa of IBD patients (MacDermott et al., 1998). The low levels of TNF$\alpha$ promote the remodeling or replacement of injured and senescent tissue by stimulating fibroblast growth. High levels of TNF- $\alpha$ was correlated with increased risk of mortality (Rink and Kirchner, 1996). In our study, the level of TNF- $\alpha$ was elevated during pretreatment of LPS in HT-29 cells. The up regulated level of TNF- $\alpha$ was down regulated by PBO treatment. This reveals the role of PBO as anti-TNF- $\alpha$ agent for treating inflammation associated with UC.

IL-6 is a major inflammatory cytokine, which has a crucial role to control the transition from neutrophil to monocyte recruitment during the transformation from acute to chronic inflammation (Melnicoff et al., 1989). In chronic inflammation, IL-6 has a detrimental role that favours mononuclear cell accumulation at the site of injury, through continuous MCP-1 secretion, angioproliferation and antiapoptotic functions on $\mathrm{T}$ cells (Atreya et al., 2000). Current study demonstrates that level of IL-6 increased in LPS induced inflammation in HT-29. The RT-PCR study of IL-6 gene shows the down regulation of IL- 6 gene in PBO treated sample. The reduced expression of gene suggests the potency of PBO, which can be used as a drug against treatment of IL-6 mediated inflammatory damage in UC.

The major inflammatory conditions associated with ulcerative colitis include mucosal inflammation and ulceration of colon tissue. The colon tissue necrosis leadings to macrophage and neutrophil infiltration to the colon tissue and increasing the disease severity and inflammation (D'Argenio et al., 2012). UC was induced by intra rectal administration of $4 \%$ acetic acid to experimental animals, which phenotypically similar to human colon inflammation (Hartmann et al., 2012).

Recently, lots of studies have indicated a common link between inflammatory bowel disease and oxidative stress. The free radicals produced during oxidative stress may lead to biological membrane lipid peroxidation, resulting in severe cell damage and play a significant role in the pathogenesis of disease (Narayanan and Chandrasekharan, 2013). In the present study, acetic acid induced animals exhibits increased levels of LPO in colon tissue, but treatment with PBO significantly reduced the increased level of LPO. Indeed, increased levels of TBARS and free radicals found in the study may damage cells as observed by histological 
investigations. Microscopic evaluation by $\mathrm{H} \& \mathrm{E}$ staining of the acetic acid-treated rat colon indicated extensive epithelial necrosis and edema with destruction of normal architecture of colonic mucosa, complete mucosal and submucosal erosion and transmural inflammation, while, rats treated with normal saline showed intact mucosa, sub mucosa muscle coats and are free from inflammation and hemorrhage. Treatment with PBO showed regenerative mucosa with mild inflammation and mildly inflamed hyperemic mucosa and its effect was comparable with rats treated with SAstandard group. These above effects may be attributed to the antiinflammatory, and cytoprotective property of PBO.

Globlet cells are reduced in number and size in ulcerative colitis, the major function of intestinal goblet cells and their major secretary product mucin is the formation of mucus layer which serve as the front line innate host defense mechanism (Kin and Ho, 2010). The microscopic examination of rat colonic mucosa of acetic acid treated group by PAS staining method showed disappearance of globlet cells and reduction in mucin content, which indicated the high degree of inflammation, while rats treated with normal saline showed abundant mucin and numerous mucin secreting globlet cells. The treatment with PBO on acetic acid induced showed remarkably increased amount of globlet cells and mucin content in the rat colonic mucosa.

From the above context, the polyphenolic fraction isolated from Brassica oleracea var. capitata f. rubra demonstrated a remarkable anti inflammatory and cytoprotective ability against experimentally induced ulcerative colitis by the reduction of inflammatory markers and cytokines, prevented oxidative damage leading to regeneration of cells. These abilities of PBO reveal its importance as an anti inflammatory therapeutic agent for ulcerative colitis treatment.

\section{REFERENCES}

Abboud PA, Hake PW, Burroughs TJ. Therapeutic effect of epigallocatechin-3-gallate in a mouse model of colitis. Eur J Pharmacol, 2008; 579:411-417.

Anderson GD, Hauser SD, McGarity KL, Bremer ME, Isakson PC, Gregory SA. Selective inhibition of cyclooxygenase (COX)-2 reverses inflammation and expression of COX-2 and interleukin 6 in rat adjuvant arthritis. J Clin Invest, 1996; 97:2672-2679.

Arapitsas P, Sjo "Merg RJP, Turner C. Characterisation of anthocyanins in red cabbage using high resolution liquid chromatography coupled with photodiode array detection and electrospray ionization-linear ion trap mass spectrometry. Food chem, 2008; 109:219-226.

Atreya R, Mudter J, Finotto S, Mullberg J, Jostock T, Wirtz S, Schutz M, Bartsch B, Holtmann M, Becker C. Blockade of interleukin-6 trans signaling suppresses $\mathrm{T}$-cell resistance against apoptosis in chronic intestinal inflammation: evidence in Crohn's disease and experimental colitis in vivo. Nat Med, 2000; 6:583-588.

Axelrod B, Cheesebrough TM, Laakso S. Lipoxygenase from soyabean. Method Enzymol, 1981; 71: 441-445.

Cho EJ, Shin JS, Noh YS, Cho YW, Hong SJ, Park JH, Lee JY, Lee KT. Anti-inflammatory effects of methanol extract of Patrinia scabiosaefolia in mice with ulcerative colitis. J Ethnopharmacol, 2011; 136:428-435

D'Argenio G, Mazzone G, Tuccillo C, Ribecco MT, Graziani G, Gravina AG, Caserta S, Guido S, Fogliano V, Caporaso N, Romano M. Apple polyphenols extract (APE) improves colon damage in a rat model of colitis. Dig Liver Dis, 2012; 44:555-562.

Fournier BM, Parkos CA. The role of neutrophils during intestinal inflammation. Mucosal Immunol, 2012; 5: 354-366.

Gillum RF, Ingram DD, Makuc DM. White blood cell count, coronary heart disease, and death: the NHANES I Epidemiologic Followup Study. Am Heart J, 1993; 125(3):855-863.

Gonzalez R, Ballester I, Lopez-Posadas R, Suarez M.D, Zarzuelo A, Martinez-Augustin O, Sanchez-de-Medina F. Effects of flavonoids and other polyphenols on inflammation. Crit Rev Food Sci, $2011 ; 51,331-362$.

Griswold DE, Adams JL. Constitutive cyclooxygenase (COX-1) and inducible cyclooxygenase (COX-2): rationale for selective inhibition and progress to date. Med Res Rev, 1996; 16: 181-186.

Gutfinge T. Polyphenols in olive oil. J Am Oil Chem Soc, 1981; 1:966-968.

Hartmann RM, Morgan Martins M I, Tieppo J, Fillmann H S, Marroni NP. Effect of Boswellia serrata on antioxidant status in an experimental model of colitis rats induced by acetic acid. Dig Dis Sci, 2012; 57:2038-2044.

Jin-Yuarn L, Chia-Yuan, I-Farn H. Characterisation of the pigment components in red cabbage (Brassica oleracea L. var.) juice and their anti-inflammatory effects on LPS-stimulated murine splenocytes. Food Chem, 2008; 109:771-781.

Kankuri E, Asmawi M.Z, Korpela R, Vapaatalo H, Moilanen E. Induction of iNOS in a rat model of acute colitis. Inflammation, 1999; 141-152.

Kevin-Pavlick P, Stephen-Laroux F, John-Fuseler, Robert-Wolf E., Laura-Gray, Jason-Hoffman, Matthew-Grisham. Role of reactive metabolites of oxygen and nitrogen in inflammatory bowel disease. Free Radical Bio Med, 2002; 33: 311-322.

Kim YS, Ho SB. Intestinal goblet cells and mucins in health and disease: Recent insights and progress. Curr Gastroenterol Rep, 2010;12: 319-330

Konturek PC, Brzozowski T, Engel M. Ghrelin ameliorates colonic inflammation. Role of nitric oxide and sensory nerves. J Physiol Pharmacol, 2009; 60:41-47.

Kusznierewicz B, Bartoszek A, Wolska L. Partial characterization of white cabbages (Brassica oleracea var. capitata f. alba) from different regions by glucosinolates, bioactive compounds, total antioxidant activities and proteins. Food Sci Tech, 2008; 41: 1-9.

Liu D, Shi J, Ibarra AC. The scavenging capacity and synergistic effects of lycopene, vitamin $\mathrm{E}$, vitamin $\mathrm{C}$, and b-carotene mixtures on the DPPH free radical. Food Sci Tech, 2008; 41:1344-9.

Loftus EV, Silverstein M D, Sandborn WJ. Ulcerative colitis in Olmsted County, Minnesota, 1940-1993: Incidence, prevalence and survival. Gut, 2000; 46: 336-343.

MacDermott RP, Sandersen IR , Reinecker HC. The central role of chemokines (chemotactic cytokines) in the immunopathogenesis of ulcerative colitis \& Crohn's disease. Inflamm Bowel Dis, 1998;4:54-67.

Maheshwari DT, Yogendra Kumar, MS, Saroj KV, Singh VK, Singh SN.Antioxidant and hepatoprotective activities of phenolic rich fraction of Seabuckthorn (Hippophae rhamnoides L.) leaves. Food Chem Toxicol, 2011; 49:2422-2428.

Martel-Pelletier J, Lajeunesse D, Reboul P, Pelletier JP. Therapeutic role of dual inhibitors of 5-LOX and COX, selective and nonselective non-steroidal anti-inflammatory drugs. Ann Rheum Dis, 2003; 62 (6): 501-509.

Melnicoff MJ, Horan PK, Morahan PS. Kinetics of changes in peritoneal-cell populations following acute inflammation. Cell Immunol, 1989; 118:178-191.

Narayanan, K , Chandrasekharan G. Protective effect of Bauhinia tomentosa onacetic acid induced ulcerative colitis by regulating antioxidant and inflammatory mediators. Inter Immunopharmacol , 2013;16:57-66.

Nilsson J, Olsson K, Engqvist G.Variation in the content of glucosinolates, hydroxycinnamic acids, carotenoids, total antioxidant capacity and low-molecular-weight carbohydrates in Brassica vegetables. J Sci Food Agric, 2003; 86: 528-38. 
Ohkawa H, Ohishi N, Yagi K. Assay for lipid peroxides in animal tissues by thiobarbituric acid reaction. Anal Biochem, 1979; 95(2): 351-358

Pandey MK, Sandur SK, Sung B, Sethi G, Kunnumakkara AB, Aggarwal BB. Butein, a tetrahydroxychalcone, inhibits nuclear factor (NF) $-\kappa B$ and NF- $\kappa B$-regulated gene expression through direct inhibition of IкB $\alpha$ kinase $\beta$ on cysteine 179 residue. J Biol Chem, 2007; 282: 1734017350 .

Park S, Park MV, Ki Lee M, Hyuk Chun J, Seo JM, Won Lee S, Al-Dhabi NA, Ju Kim S. Quantification of glucosinolates, anthocyanins, free amino acids, and vitamin $\mathrm{C}$ in inbred lines of cabbage (Brassica oleracea L.). Food Chem, 2014; 145:77-85.

Rand-Hafidh R, Ahmed-Abdulamir S, Law SV, Fatimah AB, Faridah A, Fatemeh J, Zamberi S. Inhibition of Growth of Highly Resistant Bacterial and Fungal Pathogens by a Natural Product. Open Microbiol J, 2011; 5: 96-106.

Rink L, Kirchner H. Recent Progress in the Tumor Necrosis Factor-Alpha Field. Int Arch Allergy Imm , 1996;111 (3):199-209.

Sami R, Chun-Juan L, Yan Z, Ying L, Chang-Hao S. Cabbage Phytochemicals with Antioxidant and Anti-inflammatory Potential. Asian Pac J Cancer Prev, 2013; 14(11): 6657-6662.

Sands BE, Kaplan GG, The role of TNF alpha in ulcerative colitis. J Clin Pharmacol, 2007; 47(8): 930-41

Sakamoto C. Roles of COX-1 and COX-2 in gastrointestinal pathophysiology. J Gastroenterol, 1998; 33: 618-624.

Seung-Jun L, Ji-Sun S, Hye-EunC, Kyoung-Goo L, YoungWuk C, Hyo-Jin A, Dae SJ,

Jin- Cheol J, Oh-Keun K, Jung-Hwan N, Kyung-Tae L . Chloroform fraction Of Solanum tuberosum L. cv Jayoung epidermis suppresses LPS-induced inflammatory responses in macrophages and DSS-induced colitis in mice. Food Chem Toxicol, 2014; 63:53-61.

Shama SN, Alekhya T, Sudhakar K. Pharmacognostic and phytochemical evaluation of brassica oleracea linn var capitata f rubra (The red cabbage) Pharm boil, 2012; 2(2):43-46.
Shimizu $\mathrm{T}$, Kondo K, Hayaishi $\mathrm{O}$. Role of prostaglandin endoperoxides in the serum thiobarbituric acid reaction. Arch. Biochem. Biophys, 1981; 206: 271-276.

Singh J, Upadhyay A K, Bahadur A, Singh B, Singh K P, Rai M. Antioxidant phytochemicals in cabbage(Brassica oleracea L. var. capitata). Sci Hortic, 2006;108: 233-237.

Singh V, Patil C, Jain N, Singh A, Kulkarni SK. Effect of nimesulide on acetic acid- and leukotriene-induced inflammatory bowel disease in rats. Prostag Oth Lipid M, 2003; 71:163-175.

Sklyarov AY, Panasyuk NB, Fomenko IS. Role of nitric oxidesynthase and cyclooxygenase/lipooxygenase systems in development of experimental ulcerative colitis. J Physiol Pharmacol, 2011; 62: 65-73.

Targan SR, Hanauer SB, Van Deventer SJ. A short term study of chimeric monoclonal antibody cA2 to tumor necrosis factor alpha for Crohn's disease. Crohn's Disease cA2 study Group. N Eng J Med, 1997; 337: 1029-1035.

Wiczkowski W, Szawara-Nowak D, Topolska J .Red cabbage anthocyanins: Profile, isolation, identification, and antioxidant activity. Food Res Int, 2013; 51: 303-309.

Xavier RJ, Podolsky DK. Unravelling the pathogenesis of inflammatory bowel disease. Nature, 2007; 448:427-434.

Zanfini A, Corbini G, La Rosa C. Antioxidant activity of tomato lipophilic extracts and interactions between carotenoids and atocopherol in synthetic mixtures. Food Sci Tech, 2010; 43: 67-72.

\section{How to cite this article:}

Chandrasenan P, Anjumol VM, Neethu MV, Selvaraj R, Anandan V, Jacob GM. Cytoprotective and anti inflammatory effect of polyphenolic fraction from Red cabbage (Brassica oleracea Linn var. capitata $\mathrm{f}$ rubra) in experimentally induced ulcerative colitis. J App Pharm Sci, 2016; 6 (01): 137-146. 